\title{
Genetic analysis of milk urea concentration and its genetic relationship with selected traits of interest in dairy cows
}

\author{
Y. Chen, ${ }^{1} \odot$ H. Atashi, ${ }^{1,2} \odot$ S. Vanderick, ${ }^{1} \odot$ R. R. Mota, ${ }^{1 *} \odot$ H. Soyeurt, ${ }^{1} \odot$ H. Hammami, ${ }^{1} \dagger \odot$ and N. Gengler ${ }^{1} \ddagger \odot$ \\ ${ }^{1}$ TERRA Teaching and Research Center, University of Liège, Gembloux Agro-Bio Tech (ULiège-GxABT), 5030 Gembloux, Belgium \\ ${ }^{2}$ Department of Animal Science, Shiraz University, 71441-65186 Shiraz, Iran
}

\section{ABSTRACT}

The aim of this study was to estimate genetic parameters of milk urea concentration (MU) and its genetic correlations with milk production traits, longevity, and functional traits in the first 3 parities in dairy cows. The edited data set consisted in 9,107,349 MU testday records from the first 3 parities of 560,739 cows in 2,356 herds collected during the years 1994 to 2020 . To estimate the genetic parameters of MU, data of 109 randomly selected herds, with a total of 770,016 MU test-day records, were used. Genetic parameters and estimated breeding values were estimated using a multiple-trait (parity) random regression model. Herdtest-day, age-year-season of calving, and days in milk classes (every $5 \mathrm{~d}$ as a class) were used as fixed effects, whereas effects of herd-year of calving, permanent environment, and animal were modeled using random regressions and Legendre polynomials of order 2. The average daily heritability and repeatability of MU during days in milk 5 to 365 in the first 3 parities were $0.19,0.22,0.20$, and $0.48,0.48,0.47$, respectively. The mean genetic correlation estimated among MU in the first 3 parities ranged from 0.96 to 0.97 . The average daily estimated breeding values for MU of the selected bulls $(\mathrm{n}=1,900)$ ranged from -9.09 to $7.37 \mathrm{mg} / \mathrm{dL}$. In the last $10 \mathrm{yr}$, the genetic trend of MU has gradually increased. The genetic correlation between MU and 11 traits of interest ranged from -0.28 (milk yield) to 0.28 (somatic cell score). The findings of this study can be used as the first step for development of a routine genetic evaluation for $\mathrm{MU}$ and its inclusion into the genetic selection program in the Walloon Region of Belgium.

Key words: heritability, genetic correlation, random regression, milk urea

\footnotetext{
Received April 24, 2021.

Accepted July 30, 2021.

*Present address: Council on Dairy Cattle Breeding, Bowie, MD

$\nmid$ Present address: Federal Public Service Finance, B-1030 Brussels,

‡Corresponding author: nicolas.gengler@uliege.be
} 20716. Belgium.

\section{INTRODUCTION}

Milk urea nitrogen, also expressed as milk urea concentration $(\mathrm{MU})[\mathrm{MUN}(\mathrm{mg} / \mathrm{dL})=\mathrm{MU}(\mathrm{mg} / \mathrm{dL}) / 2.14]$ as reported by Beatson et al. (2019), is included as a standard part in most milk recording systems. Regardless of the expression used, MUN or MU are indicators used to monitor the nutritional status of dairy cows and reduce nitrogen emissions to the environment (Samoré et al., 2007; Spek et al., 2013). Feed proteins are decomposed by rumen microorganisms into ammonia and branched-chain fatty acids. The ammonia is then used for de novo synthesis of amino acids by rumen microbes, whereas excess ammonia is absorbed into the bloodstream through the rumen wall and converted to urea nitrogen in the liver, which is then discharged into milk, urine, and feces (Spek et al., 2013; Ariyarathne et al., 2019). Among them, urine and feces urea $\mathrm{N}$ contribute to water pollution and gaseous $\mathrm{N}$ emissions (Hristov et al., 2019). Although it is difficult to assess urine urea $\mathrm{N}$ in routine dairy farming operations, MUN is a normal milk component (Gengler et al., 2016) that can be easily measured (Beatson et al., 2019). Even if there is not a total consensus, previous studies (e.g., Jonker et al., 1998) considered MUN as a valid predictor of urine urea N excretion. Kauffman and St-Pierre (2001) reported a linear relationship between urinary $\mathrm{N}$ and MUN in dairy cows. Some studies showed that MUN can reflect the efficiency of protein metabolism of dairy cows (e.g., Bastin et al., 2009), and the balance between CP and energy in the diet (e.g., Roy et al., 2003).

The MU varies between individuals and is affected by many factors. Literature reported among others, the factors feed compositions (Correa-Luna et al., 2019), milking time (Bendelja et al., 2011), age at calving (Wood et al., 2003), stage of lactation and season of milking (Fatehi et al., 2012; Yin et al., 2012), herd and parity (Čobanović et al., 2017; Siatka et al., 2020), and genetics (Bendelja et al., 2011; Mucha and Strandberg, 2011; Rzewuska and Strabel, 2013).

Inclusion of a given trait into a breeding program is based on the identification of its potential contribution 
to the breeding goal. For MU, its potential contribution can be explained as follows. First, some researchers demonstrated the direct interest of breeding for lower MU, or MUN, to reduce environmental effect (Bobbo et al., 2020; Marshall et al., 2020). Lower MU (or MUN) could also be linked to improved $\mathrm{N}$ use efficiency but under the hypothesis that reduced MU (or MUN) has no effect on the amount of protein produced (Jonker et al., 1998). In addition, to reduce potential unfavorable correlated responses, correlations of MU and traits included in the breeding goal have to be considered. Previous research showed that MU (or MUN) is correlated with yield traits (e.g., milk, protein, and fat yields; Yin et al., 2012; Beatson et al., 2019; Ariyarathne et al., 2021), type traits (Satoła et al., 2017b), BW (Hojman et al., 2005), SCC (Bobbo et al., 2019), and reproductive performance (Siatka et al., 2020; Kananub et al., 2020). However, results were not all indicating similar direction and strength of correlations. Therefore, more studies are needed to make the right decisions about the position of MU in the future breeding programs in the Walloon Region of Belgium.

Although MU has been included in the regular milk recording of dairy cows in the Walloon Region of Belgium since 1994, its use is restricted to management recommendations. In this context, Bastin et al. (2009) used advanced modeling (e.g., Mayeres et al., 2004) of test-day MU records in the first parity in the Walloon Region. Their study included also genetic effects but did not use EBV and did not investigate genetic correlations of $\mathrm{MU}$ with other economically important traits. Therefore, the present study can be considered also being a complement and follow-up of this previous research in the same environment but more than $10 \mathrm{yr}$ ago.

This study had 3 purposes: (1) estimating the genetic parameters of MU in the first 3 parities of Walloon dairy cows using a random regression animal model, (2) using the estimated parameters to perform a genetic evaluation for MU, and (3) estimating approximate genetic correlations between MU and 11 traits of interest currently evaluated in the Walloon Region of Belgium.

\section{MATERIALS AND METHODS}

\section{Data}

Following previous research reported by Bastin et al. (2009) and the usual trait definition in the Walloon Region of Belgium, expression as MU was preferred to MUN. The MU records were generated by the official milk recording in the Walloon Region of Belgium using mid-infrared spectrometry and commercially available instruments and calibrations from FOSS (Foss Electric A/S). Data used in this study were extracted from the generated database to create a genetic evaluation data set. Records from only the first 3 lactations were kept. Hereafter we will call the MU in the first 3 lactations MU1, MU2, and MU3, respectively. Further standard edits made were the same as for routine genetic evaluations for yield traits. Therefore, records from DIM lower than 5 and greater than $365 \mathrm{~d}$ were excluded. The value for MU was restricted between 2 and $70 \mathrm{mg} /$ dL. Finally, the 9,107,349 test-day records of the first 3 parities on 560,739 cows in 2,356 herds collected during 1994 to 2020 were kept. More than $95 \%$ of cows included were Holstein. Pedigree data were extracted from the database used for the official Walloon genetic evaluations and contained 814,023 animals (43,162 males and 770,861 females).

\section{(Co)variance Component Estimation}

Data Set. The size of the original data set and the expected complexity of the used model required that (co)variance component estimation (VCE) was done on subsamples extracted from whole genetic evaluation data set. We decided to repeat VCE 10 times, requiring 10 independent subsamples. Sampling was based on herds. Even if we identified a large number of herds in the data $(2,356)$, due to the specificity of Walloon data, many herds did not record milk over a longer period, or stopped and started milk recording over the years. Therefore, a threshold of at least 5,000 available testday records taken over the considered period of time was defined. This earmarked 629 herds to be available for the next step. Ten times, herds were randomly drawn from the pool of 629 herds until 3,000 cows with records were obtained. This was achieved for 9 subsamples with 11 herds, and in one case with 10 herds, leading to 10 subsets of a total of 109 herds randomly selected from the 629 herds. To create independent subsamples, herds could only be drawn once. Moreover, calving age for the first, second, and third parity was restricted to 22 to 37, 34 to 51, and 46 to 65 mo, respectively.

Model. Basic models used for VCE and genetic evaluation were nearly identical and based on the current genetic evaluation model used for yield traits in the Walloon Region of Belgium (Croquet et al., 2006). The following multiple-trait random regression model was used where records in each lactation were considered as separate traits:

$$
\begin{gathered}
\mathbf{y}=\mathbf{H h}+\mathbf{X b}+\mathbf{D d} \\
+\mathbf{Q}(\mathbf{C c}+\mathbf{W} \mathbf{p}+\mathbf{Z a})+\mathbf{e}
\end{gathered}
$$


where $\mathbf{y}$ is the vector of MU records in the first 3 lactations (traits MU1, MU2, and MU3), $\mathbf{h}$ is the vector of fixed herd $\times$ test-day classes, $\mathbf{b}$ is the vector of fixed age-year-season of calving classes (4 seasons were defined: December to February, March to May, June to August, and September to November), $\mathbf{d}$ is the vector of fixed lactation stage classes (72 classes, DIM was divided by into 5 -d classes, except from DIM 360 to 365 which was considered as one class), $\mathbf{c}$ is the vector of herd $\times$ year of calving common environmental random regression coefficients, $\mathbf{p}$ is the vector of permanent environmental random regression coefficients, $\mathbf{a}$ is the vector of additive genetic random regression coefficients, $\mathbf{e}$ is the vector of random residuals effects, $\mathbf{H}, \mathbf{X}$, $\mathbf{D}, \mathbf{C}, \mathbf{W}$, and $\mathbf{Z}$ are incidence matrices assigning observations to the corresponding effects, $\mathbf{Q}$ is the covariate matrix for second-order modified Legendre polynomials associated with DIM $d$ with $q_{0(d)}=1.0$, $q_{1(d)}=\quad 3.0^{0.5} x, \quad q_{2(d)}=\left(\frac{5}{4}\right)^{0.5}\left(3.0 x^{2}-1\right), \quad$ where $x=-1+2\left(\frac{d-1}{365-1}\right)$. The modified Legendre polynomials referred to the formula proposed by Gengler et al. (1999), but the DIM range was changed following the current practice in the routine genetic evaluation in the Walloon Region of Belgium.

The expected values and (co)variances associated with this model were defined as follows:

$$
\begin{gathered}
\mathrm{E}(\mathbf{y})=\mathbf{H h}+\mathbf{X} \mathbf{b}+\mathbf{D d}, \\
\mathrm{E}(\mathbf{c})=\mathrm{E}(\mathbf{p})=\mathrm{E}(\mathbf{a})=\mathrm{E}(\mathbf{e})=\mathbf{0} .
\end{gathered}
$$

The following (co)variance structures were assumed:

$$
\operatorname{Var}\left[\begin{array}{c}
\mathbf{c} \\
\mathbf{p} \\
\mathbf{a} \\
\mathbf{e}
\end{array}\right]=\left[\begin{array}{cccc}
\mathbf{C}^{*} \otimes \mathbf{I}_{c} & 0 & 0 & 0 \\
0 & \mathbf{P} \otimes \mathbf{I}_{w} & 0 & 0 \\
0 & 0 & \mathbf{G} \otimes \mathbf{A} & 0 \\
0 & 0 & 0 & \mathbf{R}
\end{array}\right],
$$

where $\mathbf{C}^{*}$ contained the coefficients of the herd $\times$ year of calving (co)variance functions $(9 \times 9$ matrix); $\mathbf{P}$ contained the coefficients of the permanent environment (co)variance functions $(9 \times 9$ matrix $) ; \mathbf{G}$ contained the coefficients of the genetic (co)variance functions $(9 \times 9$ matrix $) ; \mathbf{I}_{c}$ was an identity matrix of dimension c (number of herd $\times$ year of calving classes); $\mathbf{I}_{w}$ was an identity matrix of dimension $\mathrm{w}$ (number of cows with records); $\mathbf{A}$ was the additive genetic relationship matrix among all animals in pedigree; $\mathbf{R}$ was a diagonal matrix of dimension $\mathrm{n}$ (total number of $\mathrm{MU}$ records across the 3 lactations) with diagonal elements equal to $\sigma_{e(t)}^{2}$, which was the residual variance for trait $t$ (lactation) in which MU was recorded (MU1, MU2, MU3); and $\otimes$ represents the Kronecker product function.

Computations were done using the BLUPF90 family of programs (Misztal et al., 2018). Variance components were estimated using REML by EM algorithm as implemented in REMLF90 (version 1.84) program.

After estimating the (co)variance components separately for each subset, values were averaged and the standard deviation (SD) of each (co)variance component was computed as approximate sampling error. Homogeneity of residual variance was checked visually by computing and plotting the SD of observed residuals (difference between observed and predicted values) for each class of DIM in the first 3 parities.

\section{Genetic Parameter Calculation}

Based on estimated (co)variance components, several genetic parameters were computed. For each trait of MU1, MU2, MU3 $(t)$, heritability $\left(h_{t d}^{2}\right)$ and repeatability $\left(r e p_{t d}\right)$ were estimated for individual DIM $(d)$ between 5 and 365 as follows:

$$
\begin{gathered}
\frac{\sigma_{a(t d)}^{2}}{\left(\sigma_{a(t d)}^{2}+\sigma_{p(t d)}^{2}+\sigma_{c(t d)}^{2}+\sigma_{e(t)}^{2}\right)} \text { and } \\
\frac{\left(\sigma_{a(t d)}^{2}+\sigma_{p(t d)}^{2}+\sigma_{c(t d)}^{2}\right)}{\left(\sigma_{a(t d)}^{2}+\sigma_{p(t d)}^{2}+\sigma_{c(t d)}^{2}+\sigma_{e(t)}^{2}\right)},
\end{gathered}
$$

where $\sigma_{a(t d)}^{2}$ was the additive genetic variance for trait $t$ at DIM $d$ calculated as $\mathbf{q} \mathbf{G}_{t} \mathbf{q}^{\prime}$ where $\mathbf{G}_{t}$ was the covariance matrix $(3 \times 3)$ associated with genetic additive effects, and $\mathbf{q}$ was the vector of modified Legendre polynomial coefficients computed for DIM $d ; \sigma_{p(t d)}^{2}$ was the permanent environmental variance for trait $t$ at DIM $d$ calculated as $\mathbf{q} \mathbf{P}_{t} \mathbf{q}^{\prime}$ where $\mathbf{P}_{t}$ was the covariance matrix $(3 \times 3)$ associated with the permanent environmental effects; and $\sigma_{c(t d)}^{2}$ was the herd $\times$ year of calving variance for trait $t$ at DIM $d$ calculated as $\mathbf{q} \mathbf{C}_{t} \mathbf{q}^{\prime}$, where $\mathbf{C}_{\boldsymbol{t}}$ was the covariance matrix $(3 \times 3)$ associated with the herd $\times$ year of calving effects; $\sigma_{e(t)}^{2}$ was the residual variance for trait $t$. Average daily $h_{t d}^{2}$ and $r e p_{t d}$ were defined as the average across DIM 5 to 365. Genetic 
correlations in DIM $d$ were computed using the estimated genetic (co)variances as the ratio of the covariance to the square root of the product of the corresponding variances in DIM $d$. Phenotypic correlations were computed in the same way. Required phenotypic (co)variances were obtained as the sum of relevant (co) variance components in DIM $d$.

Genetic (co)variance for average 305-d MU was obtained by using $\mathbf{G}_{\text {lact }}=\mathbf{S}$ GS', where $\mathbf{G}_{\text {lact }}$ was the $3 \times$ 3 (co)variance matrices among average 305-d lactation MU for the 3 traits (MU1, MU2, and MU3); G was a covariance matrix $(9 \times 9)$ associated with the genetic additive effects across the 3 lactations; and $\mathbf{S}$ was a 3 $\times 9$ summation matrix that averaged the contributions of a given test day to the 305-d MU for the 3 traits (MU1, MU2, and MU3). The same approach was used to derive $\mathbf{C}_{\text {lact }}$ and $\mathbf{P}_{\text {lact }}$ matrices, which represent the herd $\times$ year of calving and permanent environmental (co)variances for average 305-d MU. Heritability for average 305-d MU was computed as the ratio of the genetic variance to the sum of the genetic, permanent environmental, herd $\times$ year of calving, and residual variances. Correlations for average 305-d MU between parities $i$ and $j$ were computed as the ratio of the average covariance-305 $\operatorname{cov}(i, j)$ to the square root of the products of the average variances-305 of MU in parities $i$ and $j$. The residual variance was considered constant during the whole lactation in each parity.

\section{Genetic Evaluation}

Genetic evaluation model was nearly identical to the current genetic evaluation model used for yield traits in the Walloon Region of Belgium (Croquet et al., 2006). Phenotypic breed differences were tested but results indicated that they could be ignored in this context. Genetic groups were included as in the routine yield evaluations distinguishing Holstein, dual-purpose Belgian Blue, and other breeds. Breeding values for the included animals were estimated according to the precondition conjugate gradient algorithm implemented in the BLUP90IOD2 (version 3.81; http://nce.ads.uga .edu/wiki/doku.php?id=readme.pcg2) program. Preparation of different types of EBV was done following the example of yield traits in the routine evaluations. Daily EBV were calculated using the following equation: $\mathrm{EBV}_{k t d}=\mathbf{q}_{m(d)}^{\prime} \mathbf{a}_{k t m}$, where $\mathrm{EBV}_{k t d}$ was the EBV of cow $k$ for trait $t$ (here MU1, MU2 and MU3) in DIM of $d$, for DIM 5 to $365 ; \mathbf{a}_{k t m}$ were the 3 solutions $\mathrm{m}$ (additive genetic random regression coefficients) of cow $k$ for trait $t$ obtained after solving the mixed-model equations; $\mathbf{q}_{m(d)}$ was the same as the $\mathbf{Q}$ in Equation [1], in which $d$ ranged from 5 to 365 . Following the example of reported EBV for yield traits that are average lacta- tion EBV of the first 3 parities, the average daily EBV value of MU in the first 3 parities was also calculated. The formula for average daily EBV was

$$
\mathrm{EBV}_{k}=\sum_{j=1}^{3} \sum_{d=1}^{305} \mathbf{q}_{m j(d)}^{\prime} \mathbf{a}_{k t m j} /(3 \times 305)
$$

where $j$ is the number of parity, and the rest of the parameters are the same as in the formula of daily EBV. The reliability (REL) of average daily EBV for MU was calculated based on the Interbull calculation method proposed by Stranden et al. (2000) as used in the Walloon routine genetic evaluation system for yield traits. This system provides also directly expected daughter contributions (EDC) as defined by Interbull. In the subsequent analysis of approximate genetic correlation with traits included, the MU in the first 3 parities were combined into one trait as suggested by Hossein-Zadeh and Ardalan (2011).

\section{Approximate Genetic Correlations}

The approximate genetic correlations between MU and 11 traits of interest were estimated using the procedure proposed by Blanchard et al. (1983) which is a generalized version of Calo's method (Calo et al., 1973) when selected bulls had very diverse REL. The 11 traits of interest included milk yield (MY), fat yield $(\mathbf{F Y})$, protein yield $(\mathbf{P Y})$, SCS, fat percentage (FP), protein percentage (PP), longevity, female fertility (FF), BCS, direct calving ease (DCE), and maternal calving ease (MCE). The calculation model and algorithm of EBV for the 11 traits of interest can be found in the documents (Belgium) submitted to Interbull (https://interbull.org/ib/geforms) or reports by Vanderick et al. (2020). To use those bulls that were commonly used in Walloon, in the first step bulls had to have at least 100 descendants registered. Then, a total of 1,900 bulls were identified as having REL for average daily EBV of MU that was greater than 0.50 associated with at least 5 daughters with MU records. Based on the data obtained for the traits included, 2 different strategies were used to calculate the approximate genetic correlations.

\section{Correlations Based on Daily EBV of MU, Yield Traits, and SCS}

Even if they are not provided in routine, daily EBV of MY, FY, PY, and SCS (4 traits) for each DIM can be generated using the genetic evaluation system of dairy cows in the Walloon Region of Belgium. In this study, we used those EBV obtained during the routine 
run of August 2020. As REL of daily EBV are not calculated in routine, the following procedure was used to get reasonable approximated REL associated with daily EBV. First lactation-based REL $\left(R E L_{305}\right)$ were transformed to EDC using the lactation heritability for each trait $\left(h_{305}^{2}\right), E D C$ representing the information content:

$$
E D C=\frac{R E L_{305}}{1-R E L_{305}} \times \frac{4-h_{305}^{2}}{h_{305}^{2}} .
$$

In the second step, the $E D C$ was back transformed to Daily-REL:

$$
R E L_{d}=\frac{E D C}{E D C+\frac{4-h_{d}^{2}}{h_{d}^{2}}},
$$

where $R E L_{\mathrm{d}}$ and $h_{d}^{2}$ were, respectively, the REL and heritability at DIM $d$ for each trait. The needed daily heritability $h_{d}^{2}$ was calculated using the official (co) variance matrix of the corresponding traits. Based on the EBV of the studied traits and the corresponding REL in the given test day, the approximate genetic correlations between MU and MY, FY, PY and SCS were calculated, for DIM 5 to 365 .

\section{Correlations Based on Selected Daily EBV of MU and EBV of Fat and Protein Percentages, Longevity, and Selected Functional Traits}

The 7 important traits of interest (FP, PP, longevity, FF, BCS, MCE, and DCE) evaluated in Walloon are not defined across a longitudinal lactation scale. Therefore, the following method was used to calculate their approximated genetic correlations with MU at different lactation stages (25, 125, 225, and 325 DIM). The EBV and REL of the 7 traits of interest, here after called studied traits, for 1,900 previously selected bulls could be obtained from the published EBV on the ELINFO website (http://www.elinfo.be/indexEN .html). First among the 1,900 previously selected bulls, based on reliabilities for the 7 studied traits with REL greater than 0.50 , a list of 1,317 qualified bulls was created. Then, based on the daily EBV of MU at selected $\operatorname{DIM}(25,125,225$, and 325) and their REL, the EBV of the 7 studied traits, and their corresponding REL, the approximate genetic correlations between these traits were calculated. Standard errors of the estimated approximate genetic correlation were obtained using 1,000 bootstrapped replicates (Chen et al., 2021).
In addition, the genetic trends for all 12 traits were reports by year of birth of the selected bulls. For genetic trend analysis of MU, average daily EBV of selected bulls $(\mathrm{n}=1,900)$ was used; whereas for the other 11 traits the official EBV of selected bulls $(\mathrm{n}=1,900$ or $\mathrm{n}$ $=1,317$ ) from the ELINFO website were used. Because the values varied greatly among traits, the EBV of all traits were standardized using the mean and SD of the bull population. In order, to achieve groups of bulls based on birth years that were large enough $(>100)$, the bulls were divided into the following 7 birth year groups: before 1992, 1992 to 1995, 1996 to 1999, 2000 to 2003,2004 to 2007,2008 to 2011, and 2012 to 2015 . The data preparation and processing were done using R (https://r-project.org).

\section{RESULTS AND DISCUSSION}

\section{Descriptive Statistics}

The description of the final edited data set $(\mathrm{n}=$ $9,107,349)$ used for genetic evaluation and the sampled data sets for $\operatorname{VCE}(\mathrm{n}=770,016)$ is presented in Table 1. The average and SD of MU for the sampled VCE data sets were slightly lower than that those found for the final edited data set. The average MU in each of the first 3 lactations ranged from 24.80 to $26.19 \mathrm{mg} / \mathrm{dL}$, which were similar to those reported by Bastin et al. (2009) for the first-parity average MU (25.51 mg/dL) of dairy cows in Walloon. These values were also consistent with those reported in previous studies (Čobanović et al., 2017; Lopez-Villalobos et al., 2018; Ariyarathne et al., 2019). However, Satoła et al. (2017b) reported a lower value for MU in Polish Holstein-Friesian cows. The differences observed for average MU can partly be attributed to different feeding management and the studied populations. The average value of MU found in this study is within the range ( 15.0 to $30.0 \mathrm{mg} / \mathrm{dL}$ ) recommended for cattle management in Germany, France, and Austria (Glatz-Hoppe et al., 2020). The coefficient of variation (CV\%) of MU ranged from 35.08 to $40.80 \%$ with a mean of $40.51 \%$, which is slightly lower than that $(42 \%)$ reported by Bastin et al. (2009).

Figure 1 shows the curves of average MU over DIM classes for the first 3 parities. The value of MU was slightly higher in the first few weeks (lowest value around DIM 23), but it quickly increased to higher levels. However, at the end of the lactation, a decreasing trend was found especially for multiparous cows. The lactation curves observed for MU during the first 305 DIM were the same as those reported by Wood et al. (2003) and Bastin et al. (2009); however, in the extended part of the lactation (i.e., after 305 DIM), the trend showed a gradual decrease. In comparison, based 
Table 1. Descriptive statistics of milk urea concentration $(\mathrm{mg} / \mathrm{dL})$ of the final edited and the used data set

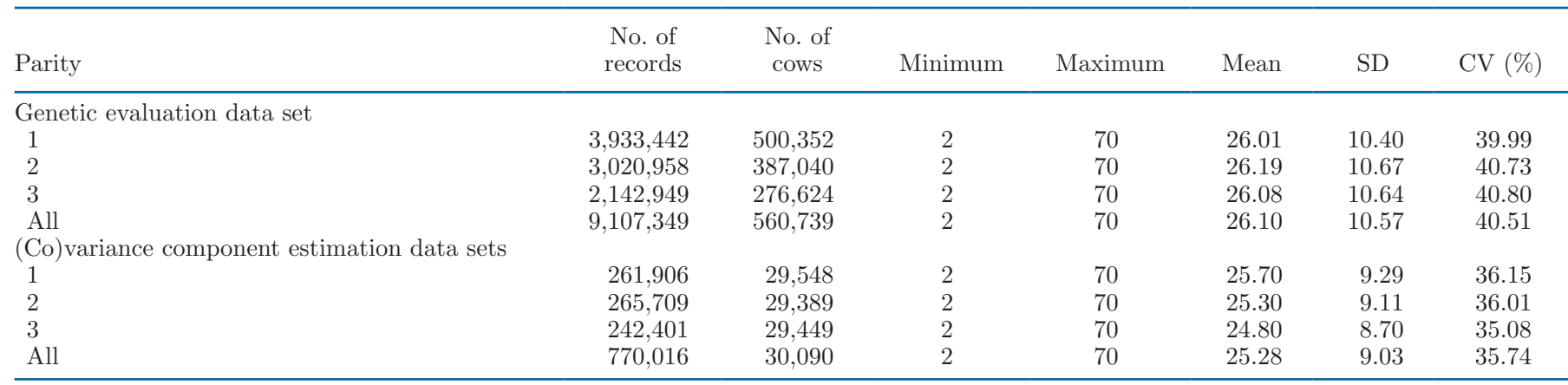

on a limited number of records $(\mathrm{n}=5,576)$, Stoop et al. (2007) reported an increasing followed by a decreasing trend for MU. Their curve was similar to the lactation curve for milk yield but with a high-level of MU maintained post lactation peak. The MU reached its lowest value in the early lactation, indicating that dairy cows have a higher $\mathrm{N}$ use efficiency at this time. It is well documented that dairy cows are in a negative energy balance state in the early stage of the lactation because the feed intake of dairy cows cannot meet their requirements. During this time, it can be assumed that cows use $\mathrm{N}$ as efficiently as possible which can explain, at least in part, the obtained results.

\section{Genetic Parameters}

The estimated variances for all random effects of MU were for all parities higher at the beginning and the end of the lactation, lower in the middle, and reached their maximum levels at 365 DIM (Figure 2). Figure 2C shows that the additive genetic variance of MU reached its minimum level at around 50 DIM, whereas its maximum value was found at DIM 365. Our results were in agreement with those reported previously (Bastin et al., 2009; Rzewuska and Strabel, 2013; Ariyarathne et al., 2019). The addition of the herd $\times$ year of calving random effect in the model helped to avoid an excessive border effect of the additive genetic variance exceeding 305 DIM (Figure 2A).

The estimated variance components for $\mathrm{MU}$ in the first 3 parities averaged over the lactation period (DIM 5-365) along with their SD are presented in Table 2. The additive genetic variances for the first, second, and third parity accounted for $18.45,21.34$, and $19.69 \%$ of the total phenotypic variance, respectively. Furthermore, the calculated SD of the observed residuals ac-

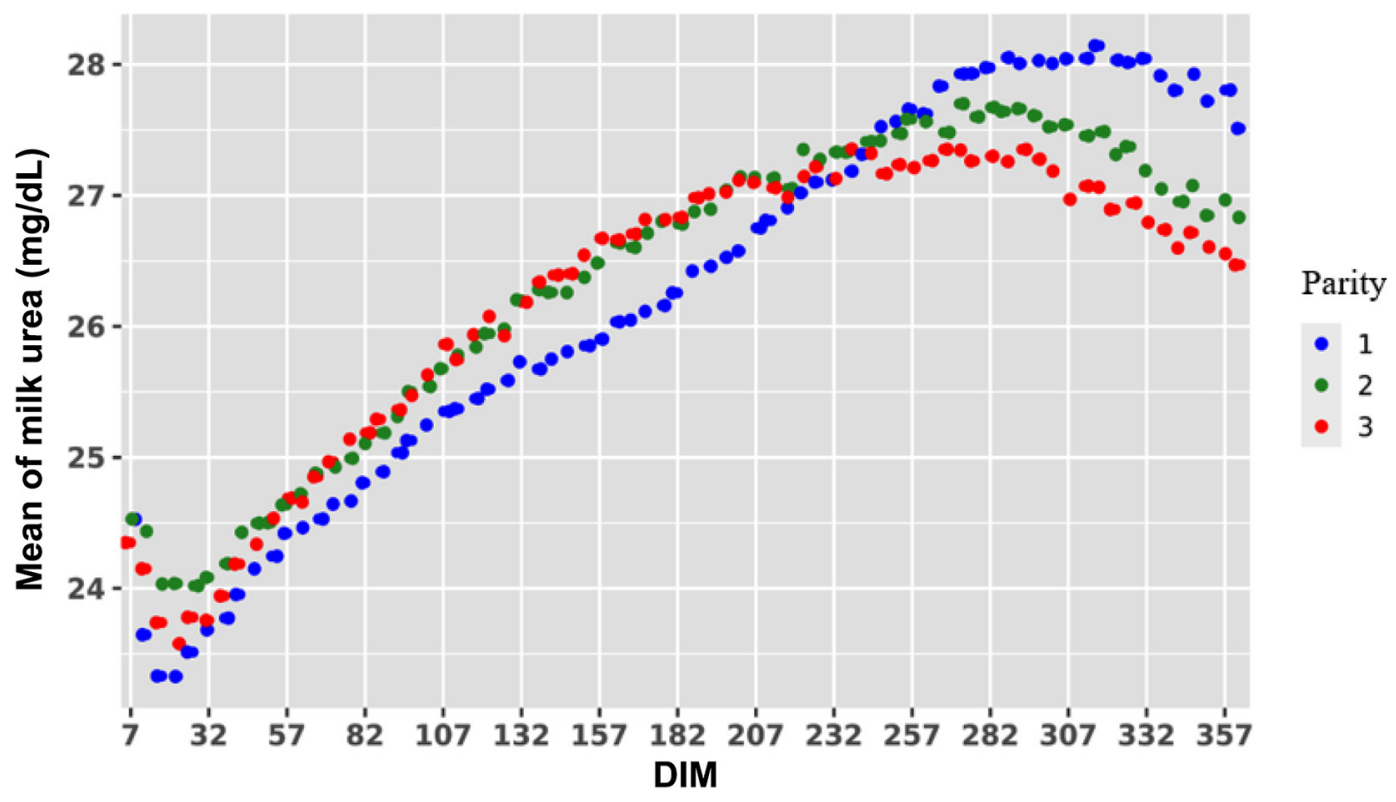

Figure 1. Lactation curves for milk urea concentration within classes of DIM (represented by their average DIM) for the first 3 parities $(\mathrm{n}=9,107,349)$. 
cumulated across the 10 VCE subsets for each DIM class were nearly horizontal except for the beginning (first 15 DIM) and the end (last 30 DIM) of the lactation (Figure 3). The higher residual variance observed at the beginning of lactation could also be attributed to larger changes in body metabolism during this period (e.g., negative energy balance) that could not be perfectly described by our model. There are at least 2 potential explanations for the decrease at the end of the lactation. First, the observed environmental vari- ances tended to very high at the end of the lactations, the slight decrease could be a compensation. The lower residual variance observed at the end of lactation may also be due to the decrease in the amount of data available in this period (half compared with the previous classes). As illustrated in Figure 3, based on the visual inspection, despite these very slight deviations, the overall horizontal nature of the residual SD curves can be confirmed. This strengthens the assumption that modeling homogeneous residuals across the lactation
A

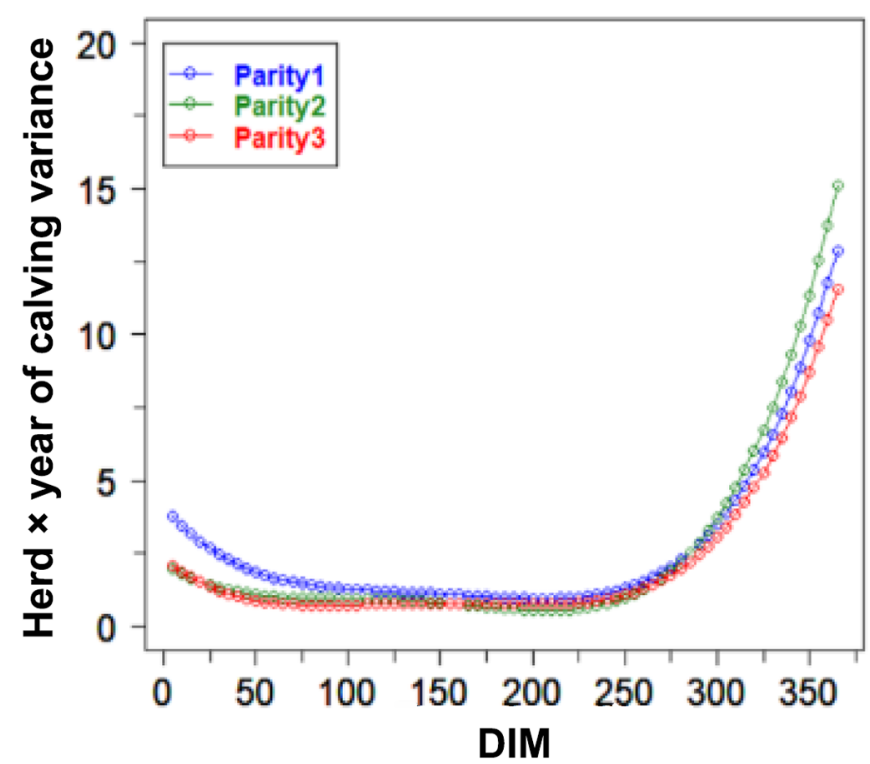

C

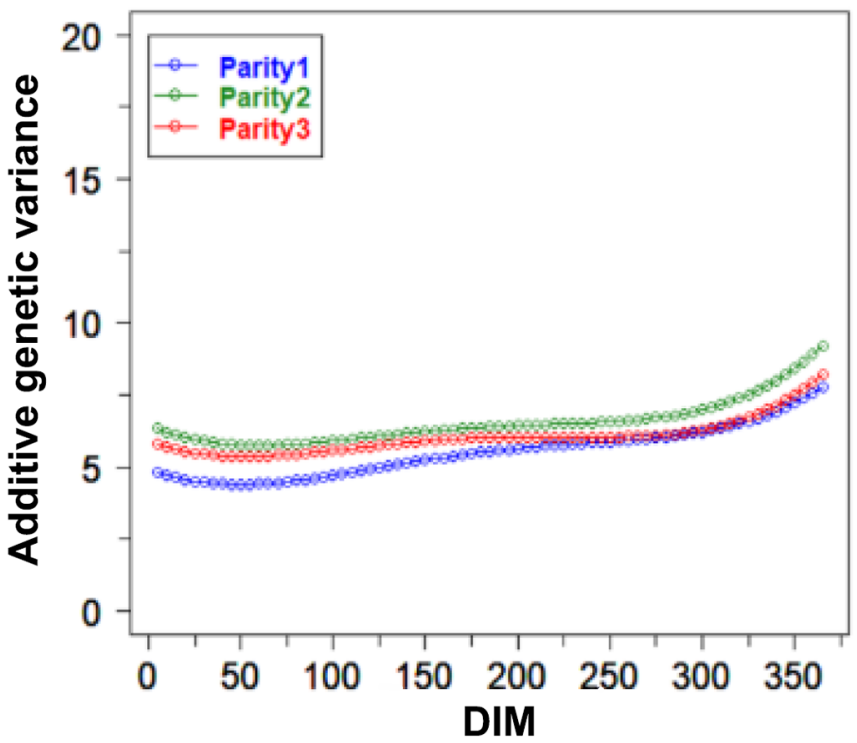

B

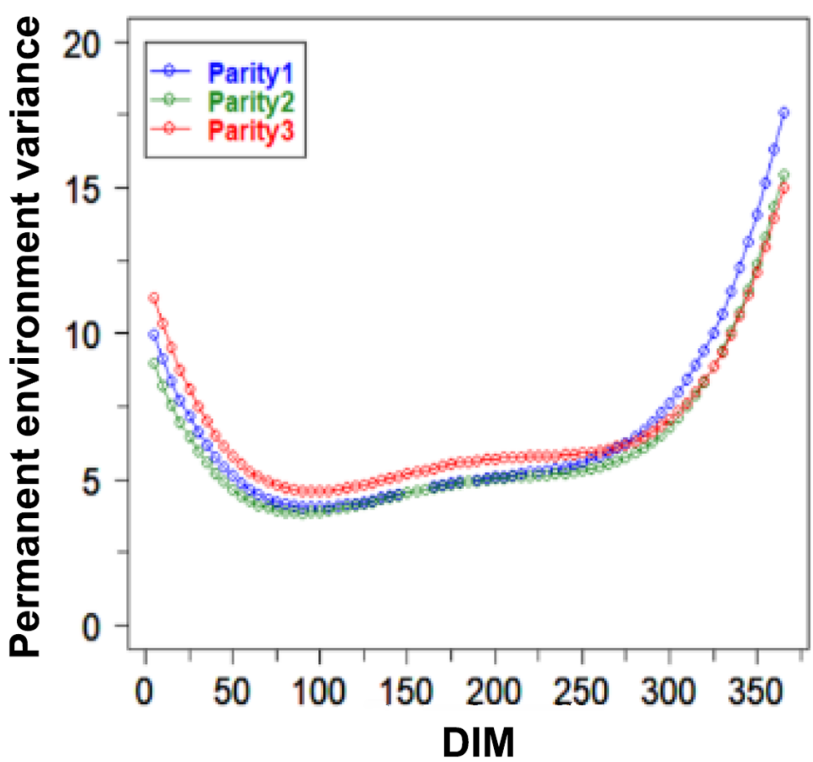

D

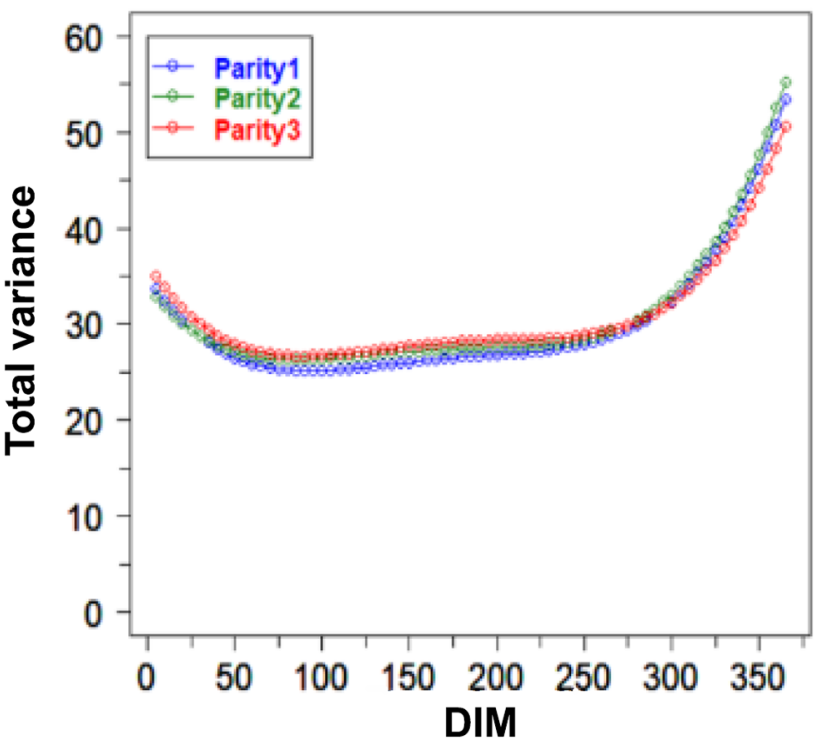

Figure 2. Variance components estimated for milk urea concentration over DIM for the first 3 parities. 
Table 2. Mean (approximate SE computed from SD of the 10 sampling subsets) of daily $h^{2}$, repeatability, herd $\times$ year of calving variance $\left(\sigma_{c}^{2}\right)$, permanent environmental variance $\left(\sigma_{p}^{2}\right)$, additive genetic variance $\left(\sigma_{a}^{2}\right)$, and total variance $\left(\sigma_{\text {total }}^{2}\right)$ of milk urea concentration for each parity throughout the lactation

\begin{tabular}{lcccccc}
\hline Parity & $h^{2}$ & Repeatability & $\sigma_{c}^{2}$ & $\sigma_{p}^{2}$ & $\sigma_{a}^{2}$ & $\sigma_{\text {total }}^{2}$ \\
\hline 1 & $0.19 \pm 0.02$ & $0.48 \pm 0.08$ & $2.70 \pm 2.73$ & $6.57 \pm 3.06$ & $5.52 \pm 0.86$ & $29.92 \pm 6.41$ \\
2 & $0.22 \pm 0.02$ & $0.48 \pm 0.08$ & $2.51 \pm 3.36$ & $6.07 \pm 2.56$ & $6.55 \pm 0.78$ & $30.69 \pm 6.58$ \\
3 & $0.20 \pm 0.02$ & $0.47 \pm 0.07$ & $2.11 \pm 2.52$ & $6.72 \pm 2.35$ & $6.05 \pm 0.61$ & $30.73 \pm 5.30$ \\
\hline
\end{tabular}

is a valid assumption that simplified the used model. Especially for genetic evaluations a simpler model is advantageous avoiding preadjustment or weighting records to correct for heteroscedasticity. The average (SD) residual variances across the $10 \mathrm{VCE}$ subsets for MU1, MU2, and MU3 were 15.13 (0.87), 15.56 (0.92), and $15.86(1.01)$, respectively.

The heritability and repeatability estimates of MU by DIM are presented in Figure 4 . The heritability estimates showed an increasing phase from the beginning of the lactation, reached its maximum level at around 215 DIM, then decreased to the end of the lactation (from 0.13 to 0.23 ), which is in a close agreement with that reported by Yin et al. (2012). However, the trend of heritability reported by Rzewuska and Strabel (2013) was different, which may be, at least in part, due to different models used or different populations studied. The MU heritabilities averaged across lactation were $0.19,0.22$, and 0.20 , for the first, second, and third parity, respectively (Table 2), which are in a close agreement with those reported by Mitchell et al. (2005), Mucha and Strandberg (2011), and LopezVillalobos et al. (2018). However, these values were higher than those reported by König et al. (2008) and Bastin et al. (2009), and lower than those reported by Miglior et al. (2007) and Ariyarathne et al. (2019). The average $305-\mathrm{d}$ heritabilities of MU were $0.52,0.60$, and 0.54 , respectively, in the first 3 parities (Table 3 ), which were similar to the maximum average heritability of MUN (0.59 in the second parity) reported by Wood et al. (2003). The trend of repeatability for MU over DIM resembled a "U" shape (from 0.40 to 0.72 ) and reached its maximum at 365 DIM, which is in agreement with Ariyarathne et al. (2021). The repeatability

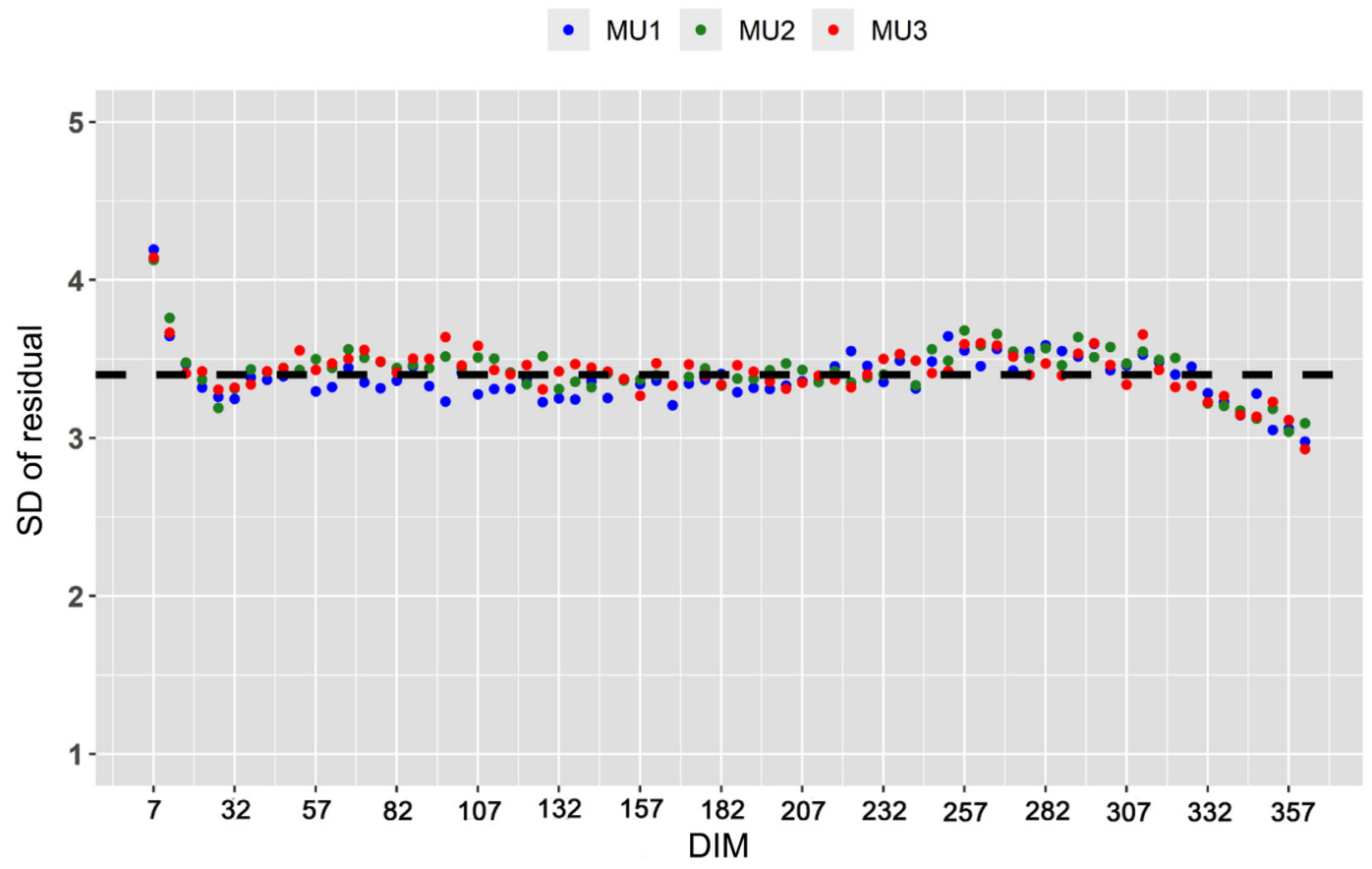

Figure 3. The standard deviation (SD) of the observed residual within classes of DIM (represented by their average DIM) for milk urea concentration of the first 3 parities in the sampled data set $(n=770,016)$ used for (co)variance component estimation (MUx: milk urea concentration in parity $\mathrm{x}$, where $\mathrm{x}$ is 1,2 , or 3 ). 
estimates of MU averaged over lactation were 0.48 , 0.48 , and 0.47 , respectively, for the first, second, and third parities (Table 2), which are in line with those reported in previous studies (Ariyarathne et al., 2019, 2021; Beatson et al., 2019).

\section{Correlations Among the First 3 Parities}

The genetic and phenotypic correlations of $\mathrm{MU}$ among the first 3 parities are presented in Figure 4C and $\mathrm{D}$, respectively. The genetic correlations of $\mathrm{MU}$
Table 3. Average ( \pm SE) 305-d heritabilities (diagonal), average 305d genetic correlations (above diagonal), and average 305-d phenotypic correlations (below diagonal) of milk urea concentration among the first 3 parities in Walloon dairy cows computed from the 10 sampling subsets (approximate SE computed from observed SD)

\begin{tabular}{lccc}
\hline Parity & 1 & 2 & 3 \\
\hline 1 & $0.52 \pm 0.08$ & $0.97 \pm 0.01$ & $0.96 \pm 0.02$ \\
2 & $0.84 \pm 0.03$ & $0.60 \pm 0.07$ & $0.97 \pm 0.07$ \\
3 & $0.76 \pm 0.03$ & $0.85 \pm 0.02$ & $0.54 \pm 0.07$ \\
\hline
\end{tabular}

A

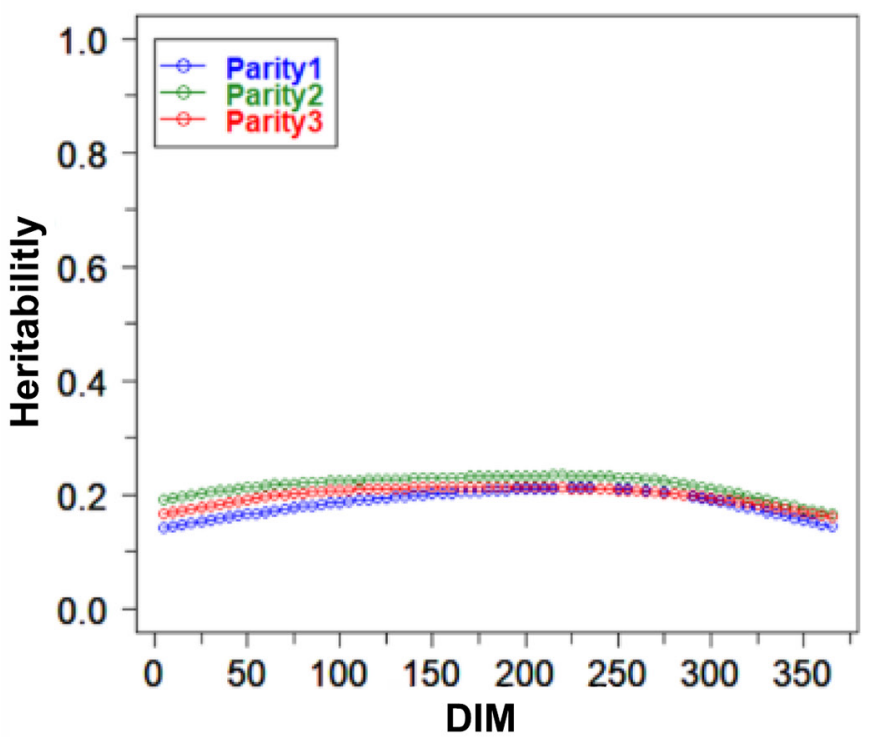

C

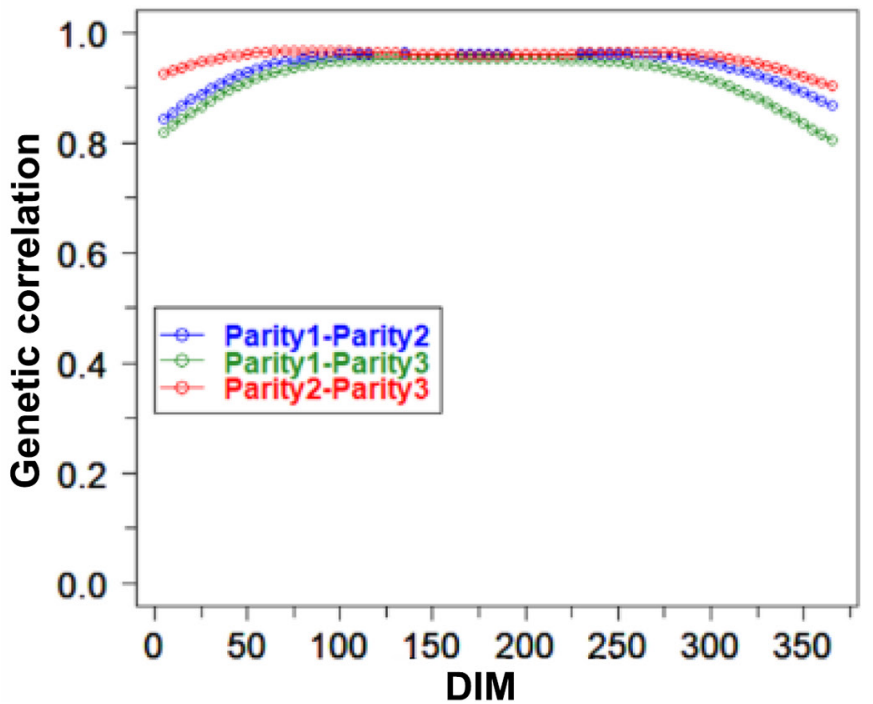

B

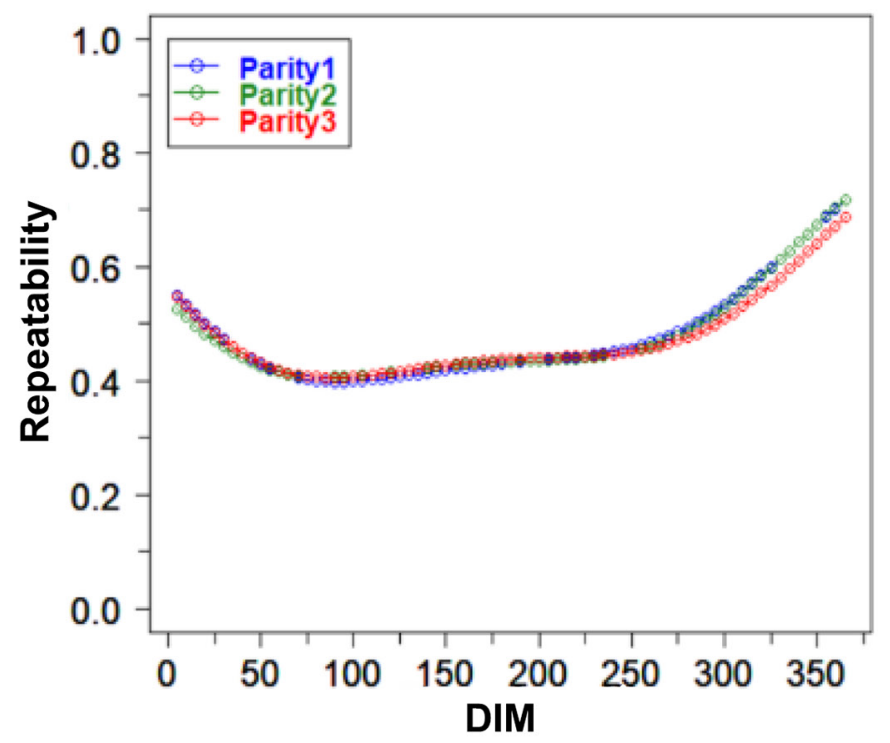

D

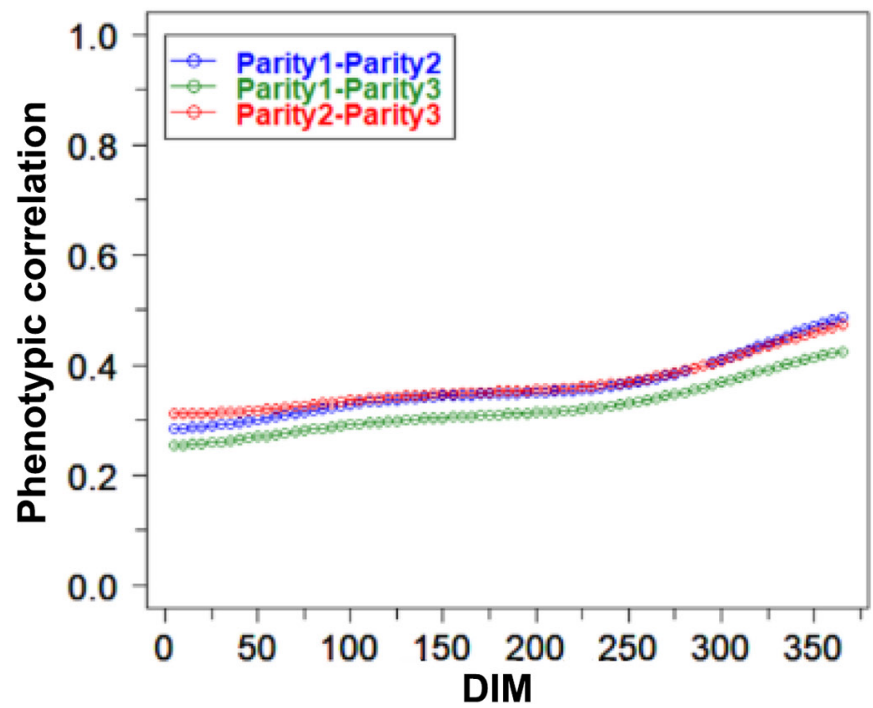

Figure 4. Heritability (A), repeatability (B), genetic correlation (C), and phenotypic correlation (D) of milk urea concentration over DIM in the first 3 parities. 

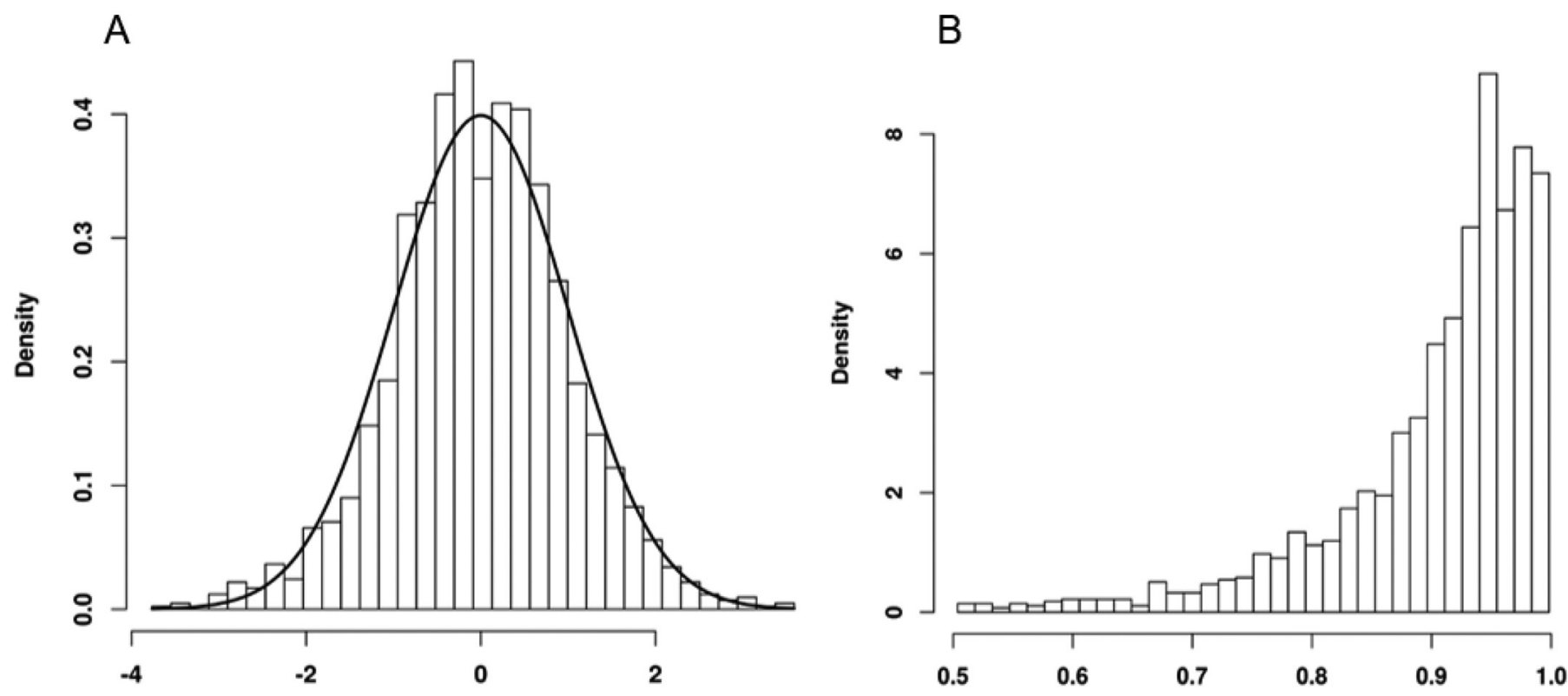

Figure 5. Distribution of standardized average daily EBV (A) and its reliability (B) for milk urea concentration of the selected bulls $(\mathrm{n}=1,900)$.

among the first 3 parities were lower at the beginning and at the end of the lactation, whereas their maximum levels were found in the middle of the lactation. The average genetic correlations of MU calculated among the first 3 parities during DIM 5 to 365 ranged from 0.92 to 0.96 . The obtained results are similar to those reported by Hossein-Zadeh and Ardalan (2011) and Rzewuska and Strabel (2013), but higher than those reported by Satoła et al. (2017a). The 305-d genetic correlation of MU among the first 3 parities ranged from 0.96 to 0.97 (Table 3), which is in a close agreement with that found between the first and second parity by Mitchell et al. (2005).

The phenotypic correlations of MU among the first 3 parities increased with increasing DIM and ranged from 0.32 to 0.37 in agreement with those reported by Hossein-Zadeh and Ardalan (2011). The 305-d phenotypic correlations of MU among the first 3 parities was relatively high and ranged from 0.76 to 0.85 (Table 3 ).

\section{Genetic Evaluation and Trend}

The Figure 5 showed the distribution of standardized average daily EBV of MU and their associated REL for the selected bulls (mean $=0, \mathrm{SD}=1$ ). The average daily EBV of 1,900 bulls and the corresponding REL ranged from -9.09 to $7.37 \mathrm{mg} / \mathrm{dL}$ and 0.50 to 0.99 $($ mean $=0.90)$, respectively. The relatively high REL found for average daily EBV may be attributed to the high 305-d heritability of MU. In addition, only bulls with at least 100 daughters in the pedigree were selected in this study which also can explain the relatively high REL found for average daily EBV.

Figure 6 shows the genetic trends for the MU, production, longevity, and functional traits involved in this study. The genetic trend of MU gradually decreased from the first to the third group (1996-1999), which reached its minimum level, then gradually increased to the last group (2012-2015) to reach the maximum level. It has been also shown that the $\mathrm{N}$ use efficiency of the local cattle population decreased gradually in the past 20 yr. The observed rapid increased in longevity, DCE, and MCE and their positive genetic correlations with $\mathrm{MU}$ (the results show in the next section), may explain a part of this finding. Only SCS showed a declined trend during the last $20 \mathrm{yr}$; however, indicating that genetic selection has also improved the udder health of the studied cattle population. Moreover, decreasing SCS can be associated with a lower rate of mastitis and therefore higher longevity.

\section{Approximate Genetic Correlations with Other Traits of Interest}

The approximate genetic correlations between $\mathrm{MU}$ and MY, FY, PY, and SCS were estimated based on the daily EBV of the traits. The mean (SD) of the REL (5 to 365 DIM) of daily EBV of 1,900 selected bulls for the examined traits ranged from $0.91(0.04)$ to 0.95 (0.07). The mean (SD) of the REL of EBV of 

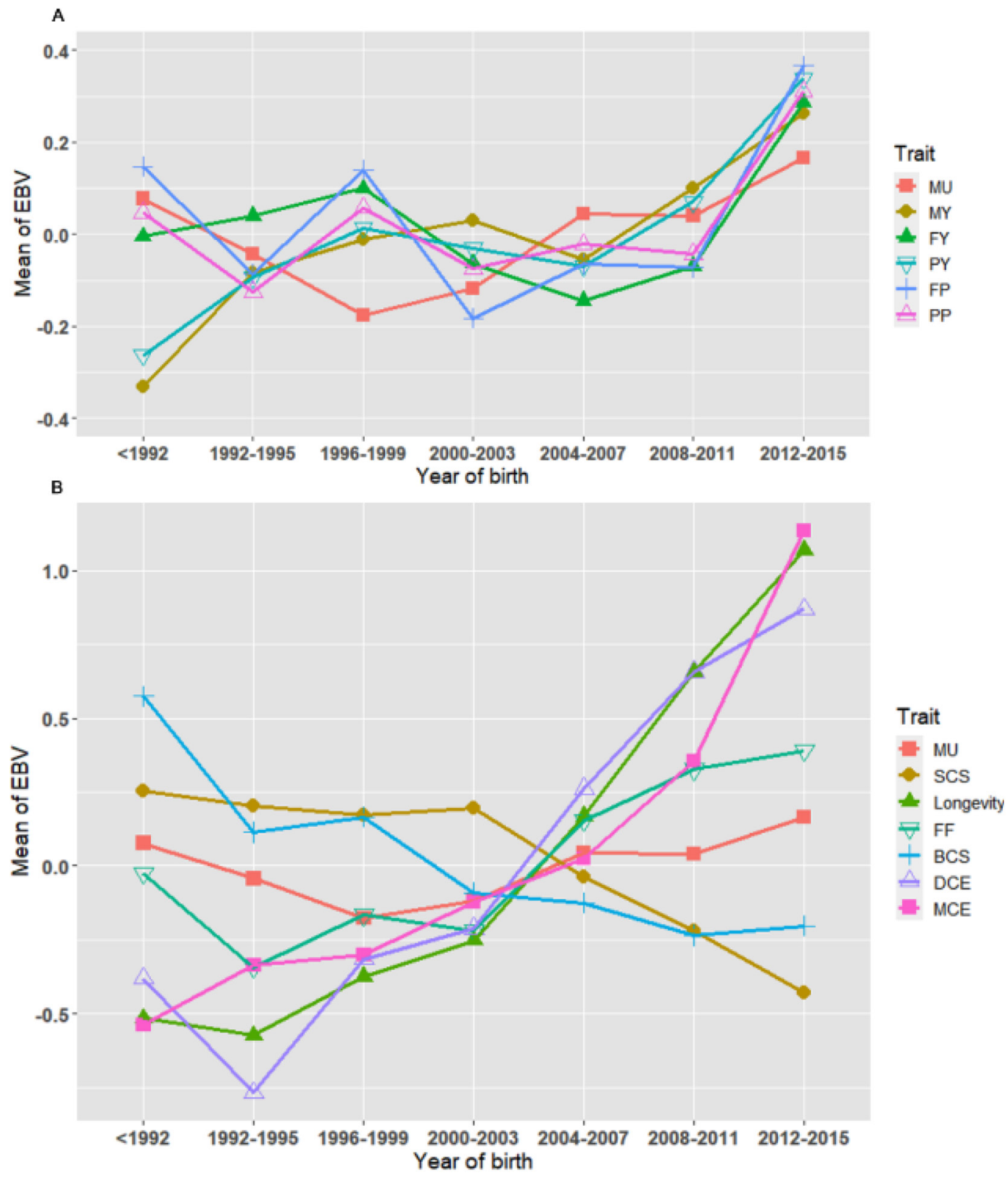

Figure 6. Genetic trend of milk urea concentration (MU), milk yield (MY), fat yield (FY), protein yield (PY), SCS, fat percentage (FP), protein percentage (PP), longevity, female fertility (FF), BCS, direct calving ease (DCE), and maternal calving ease (MCE) by year of birth of selected bulls ( $\mathrm{n}=1,900$ for MU, FY, PY, SCS, and $\mathrm{n}=1,317$ for FP, PP, longevity, FF, BCS, DCE, MCE).

1,317 bulls selected for the rest of traits included (FP, $\mathrm{PP}$, longevity, BCS, FF, DCE, MCE) ranged from 0.72 (0.05) to $0.92(0.09)$.

As shown in Figure 7, the range of approximate genetic correlations between $\mathrm{MU}$ and production traits (MY, FY, and PY) was found to be from -0.25 to -0.01 , indicating that selection for decreasing $\mathrm{MU}$ is also associated with increasing milk production traits. Low negative genetic correlation was found between MU and MY, which is in agreement with Samoré et al. (2007). However, Lopez-Villalobos et al. (2018) and Ariyarathne et al. (2021) reported that MU had a moderately positive genetic correlation with milk yield in dairy cows in New Zealand. Only grass-based diets are very common in New Zealand, but not in Belgium, where complementing grazing by energy rich feedstuff is rather standard. These important differences may cause genetic $\times$ environmental interaction that could explain the observed differences. The differences found among the results reported in different studies may be 


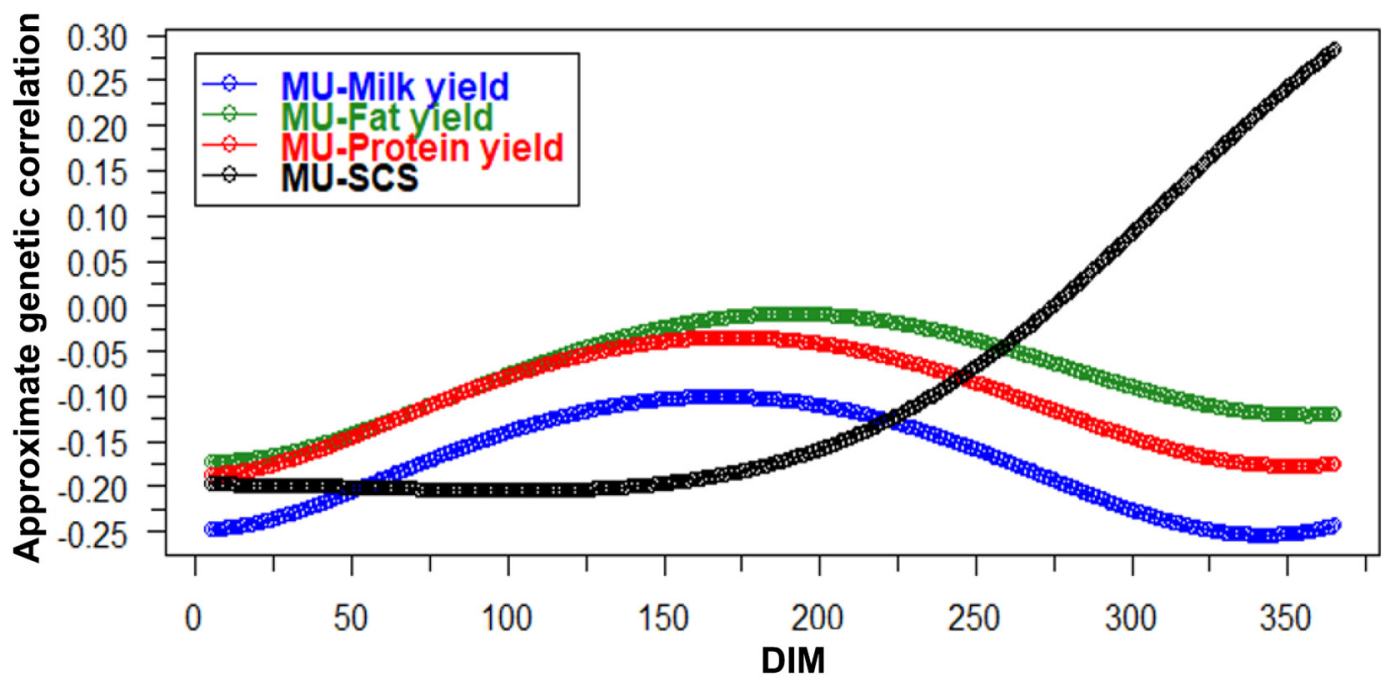

Figure 7. Approximate genetic correlation estimated between milk urea concentration (MU), milk yield, fat yield, protein yield, and SCS evaluated by EBV of selected bulls $(\mathrm{n}=1,900)$ over DIM.

attributed to the difference in the genetic background of populations studied, and different procedures used. The trait MU was weakly correlated with FY and PY (-0.19 to -0.01$)$. Mucha and Strandberg (2011) reported weak negative to weak positive genetic correlation between MUN and PY and FY. However, there are studies (e.g., Wood et al., 2003; Stoop et al., 2007) that reported positive genetic correlation between $\mathrm{MU}$ and FY or PY. The approximate genetic correlation found between MU and SCS ranged from -0.20 to 0.28 (Figure 7). Rzewuska and Strabel (2013) reported a negative genetic correlation between MU and SCS in Polish dairy cattle. Miglior et al. (2007) also found a negative genetic correlation between MUN and SCS for the first 3 parities of Canadian Holstein cows. It is well documented that the $\mathrm{N}$ use efficiency in dairy cows decreased (increased MU), but the probability of suffering from mastitis increased (increased SCS) in the late lactation. We speculate that this could be one of the reasons why genetic correlation between MU and SCS increased from a negative genetic correlation at the beginning of the lactation to a positive genetic correlation in the late part of the lactation.

The approximated genetic correlations found between MU and traits including FP, PP, longevity, FF, BCS, $\mathrm{DCE}$, and $\mathrm{MCE}$ are presented in Table 4. Moreover, we found that the genetic correlations between $\mathrm{MU}$ and FP and PP slightly changed during the lactation. The MU had a positive approximated genetic correlation with FP and PP, which is in agreement with Miglior et al. (2007). However, Bobbo et al. (2020) reported that genetic correlations of MUN and FP or PP were negative, which may be due the difference genetic background of the breeds considered in their study (i.e., Brown Swiss cows).

The approximated genetic correlation between $\mathrm{MU}$ and longevity ranged from -0.02 to 0.27 , which is in agreement with Miglior et al. (2006), which used

Table 4. Approximate genetic correlation ${ }^{1}$ and associated SE between milk urea concentration and selected functional traits evaluated in the selected bulls $(\mathrm{n}=1,317)$

\begin{tabular}{|c|c|c|c|c|}
\hline Trait & DIM $25^{2}$ & DIM 125 & DIM 225 & DIM 325 \\
\hline \multicolumn{5}{|l|}{ Milk composition } \\
\hline Fat percentage & $0.23 \pm 0.03$ & $0.14 \pm 0.03$ & $0.15 \pm 0.03$ & $0.22 \pm 0.03$ \\
\hline Protein percentage & $0.20 \pm 0.03$ & $0.15 \pm 0.03$ & $0.19 \pm 0.03$ & $0.26 \pm 0.03$ \\
\hline Longevity & $0.27 \pm 0.03$ & $0.27 \pm 0.03$ & $0.18 \pm 0.03$ & $-0.02 \pm 0.03$ \\
\hline Female fertility & $0.15 \pm 0.03$ & $0.12 \pm 0.03$ & $0.09 \pm 0.03$ & $0.05 \pm 0.03$ \\
\hline BCS & $-0.03 \pm 0.03$ & $-0.08 \pm 0.03$ & $-0.01 \pm 0.04$ & $0.18 \pm 0.04$ \\
\hline
\end{tabular}

${ }^{1}$ Approximate genetic correlation was estimated using the procedure proposed by Blanchard et al. (1983).

${ }^{2} \mathrm{EBV}$ of milk urea concentration in corresponding DIM: 25, 125, 225, or 325 . 
phenotype data to estimate the correlations. Miglior et al. (2006) using 1,568,952 MUN records, reported that an increased MUN was associated with decreased risk of culling in Holstein cows. The approximated genetic correlation found between $\mathrm{MU}$ and $\mathrm{FF}$ ranged from 0.05 to 0.15 , which was consistent with Mucha and Strandberg (2011) and Rzewuska and Strabel (2015). Mucha and Strandberg (2011) used 6, and Rzewuska and Strabel (2015) used 5 indicators for measuring FF, whereas in our study, FF was defined as pregnancy rate (Vanderick et al., 2020). The slightly positive genetic relationship found between $\mathrm{MU}$ and FF may be due to the slightly negative correlation between MU and MY and the relatively strong expectation that there is a negative correlation between FF and MY. Siatka et al. (2020) reported that MU had a significant negative effect on the fertility of high-yielding dairy cattle. Moreover, the approximate genetic correlation found between MU and FF was lower at the end of the lactation (325 DIM). In summary, it turns out that MU, longevity and functional traits (except for BCS) were positively genetically related in the early stage of lactation, and gradually weaken in the later stage.

The approximate genetic correlation found between MU and BCS was close to zero in early and mid lactation, but a stronger correlation was found in late lactation. Loker et al. (2012) reported that the genetic correlation between MUN and BCS was relatively high in the early and late stages of lactation. High levels of MU in late lactation may indicate excessive protein in the feed, which may improve the BCS of cows. A weakly positive genetic correlation was found between MU and calving ease (direct and maternal) in early lactation.

This research leads to several issues to be considered in future research. First, more than $95 \%$ of the cows in this study were Holstein. Strictly speaking, because the phenotypic means of MU and its genetic parameters were reported to be different for specific cattle breeds (e.g., Brown Swiss; Doska et al., 2012; Bobbo et al., 2020), our results can only be considered representative of the Holstein breed in the Walloon Region of Belgium. Therefore, complementary research for dualpurpose Belgian Blue, the second most common breed milked in dairy farms in the Walloon Region, is ongoing simultaneously. Second, genomic selection is now commonly used in dairy cattle, and this is also the case in the Walloon Region. Therefore, we will extend this research toward the use of genomic tools. Finally, this study did not solve the question about the link between MU and $\mathrm{N}$ use efficiency. As reported by Chen et al. (2021), we have defined novel predicted N use efficiency traits based on mid-infrared spectral data. Because of the availability of an historical spectral database in the
Walloon Region, we are investigating the link between MU and these novel traits. These results will also be useful to develop strategies on how MU EBV should be defined and how they should be used to be useful for reducing environmental impact and improving $\mathrm{N}$ efficiency.

\section{CONCLUSIONS}

The genetic parameters of MU were estimated using a random regression model for the first 3 parities. The average daily heritability of MU from DIM 5 to 365 in the first 3 parities ranged from 0.19 to 0.22 . High genetic correlations were found among MU in the first 3 parities, so we recommend combining the 3 traits into 1. The approximated genetic correlation found between MU and SCS ranged from -0.20 to 0.28 , and the corresponding genetic correlation found between MU and production traits (MY, FY, and PY) ranged from -0.25 to -0.01 , indicating that selection for increasing milk production traits and decreasing SCS should lead to decreasing MU. Observation of genetic trends revealed more complex relationships. Genetic correlations between MU and longevity, FF, DCE, and MCE were weakly positive in early lactation $(0.12-0.27)$. The findings of this study can be used as the first step in developing a routine genetic evaluation for MU and its inclusion into the genetic selection program in the Walloon Region of Belgium.

\section{ACKNOWLEDGMENTS}

The China Scholarship Council (Beijing) is acknowledged for funding the PhD project of Yansen Chen. The authors acknowledge the support of the Walloon Government (Service Public de Wallonie - Direction Générale Opérationnelle Agriculture, Ressources Naturelles et Environnement, SPW-DGARNE; Namur, Belgium) and the use of the computation resources of the University of Liège - Gembloux Agro-Bio Tech (Gembloux, Belgium) provided by the technical platform Calcul et Modélisation Informatique (CAMI) of the TERRA Teaching and Research Centre, partly supported by the National Fund for Scientific Research (F.R.S.-FNRS, Brussels, Belgium) under Grants No. T.0095.19 (PDR "DEEPSELECT") and J.0174.18 (CDR "PREDICT-2"). Computational resources have been provided by the Consortium des Équipements de Calcul Intensif (CÉCI) funded by the National Fund for Scientific Research (F.R.S.-FNRS, Brussels, Belgium) under Grant No. 2.5020.11. The authors acknowledged the support of the Walloon Breeder Association (awé groupe, Belgium). The authors have not stated any conflicts of interest. 


\section{REFERENCES}

Ariyarathne, H. B. P. C., M. Correa-Luna, H. T. Blair, D. J. Garrick, and N. Lopez-Villalobos. 2019. Estimation of heritabilities for milk urea and efficiency of crude protein utilization by day of lactation in a New Zealand dairy cow herd. N. Z. J. Anim. Sci. Prod. 79:183-187.

Ariyarathne, H. B. P. C., M. Correa-Luna, H. T. Blair, D. J. Garrick, and N. Lopez-Villalobos. 2021. Genetic parameters for efficiency of crude protein utilisation and its relationship with production traits across lactations in grazing dairy cows. N. Z. J. Agric. Res. 64:62-82. https://doi.org/10.1080/00288233.2020.1726414.

Bastin, C., L. Laloux, A. Gillon, F. Miglior, H. Soyeurt, H. Hammami, C. Bertozzi, and N. Gengler. 2009. Modeling milk urea of Walloon dairy cows in management perspectives. J. Dairy Sci. 92:35293540. https://doi.org/10.3168/jds.2008-1904.

Beatson, P. R., S. Meier, N. G. Cullen, and H. Eding. 2019. Genetic variation in milk urea nitrogen concentration of dairy cattle and its implications for reducing urinary nitrogen excretion. Animal 13:2164-2171. https://doi.org/10.1017/S1751731119000235.

Bendelja, D., Z. Prpić, N. Mikulec, Z. Ivkić, J. Havranek, and N. Antunac. 2011. Milk urea concentration in Holstein and Simmental cows. Mljekarstvo 61:45-55. https://hrcak.srce.hr/65204.

Blanchard, P. J., R. W. Everett, and S. R. Searle. 1983. Estimation of genetic trends and correlations for Jersey cattle. J. Dairy Sci. 66:1947-1954. https://doi.org/10.3168/jds.S0022-0302(83)82033 -5 .

Bobbo, T., M. Penasa, A. Rossoni, and M. Cassandro. 2020. Short communication: Genetic aspects of milk urea nitrogen and new indicators of nitrogen efficiency in dairy cows. J. Dairy Sci. 103:9207-9212. https://doi.org/10.3168/jds.2020-18445.

Bobbo, T., C. Roveglia, M. Penasa, G. Visentin, R. Finocchiaro, and M. Cassandro. 2019. Genetic relationships of alternative somatic cell count traits with milk yield, composition and udder type traits in Italian Jersey cows. Anim. Sci. J. 90:808-817. https://doi.org/ 10.1111/asj.13204.

Calo, L. L., R. E. McDowell, L. D. VanVleck, and P. D. Miller. 1973. Genetic aspects of beef production among Holstein-Friesians pedigree selected for milk production. J. Anim. Sci. 37:676-682. https: //doi.org/10.2527/jas1973.373676x.

Chen, Y., S. Vanderick, R. R. Mota, and C. Grelet., GplusE Consortium, andGengler, N. 2021. Estimation of genetic parameters for predicted nitrogen use efficiency and losses in early lactation of Holstein cows. J. Dairy Sci. 104:4413-4423. https://doi.org/10 $.3168 /$ jds. $2020-18849$

Čobanović, K., D. Kučević, M. Plavšić, and V. Bogdanović. 2017. Impact of non nutritional factors on milk urea concentration and its relationship with production and fertility traits in Vojvodina dairy herds. Mljekarstvo 67:267-276. https://doi.org/10.15567/ mljekarstvo.2017.0404.

Correa-Luna, M., D. Donaghy, P. Kemp, M. Schutz, and N. Lopezvillalobos. 2019. Effect of genetic merit for milk urea on milk production and efficiency of crude protein utilization of grazing cows with contrasting supplement inclusion. N. Z. J. Anim. Sci. Prod. 79:112-117.

Croquet, C., P. Mayeres, A. Gillon, S. Vanderick, and N. Gengler. 2006. Inbreeding depression for global and partial economic indexes, production, type, and functional traits. J. Dairy Sci. 89:22572267. https://doi.org/10.3168/jds.S0022-0302(06)72297-4.

Doska, M. C., D. F. F. da Silva, J. A. Horst, A. A. Valloto, P. Rossi Jr., and R. de Almeida. 2012. Sources of variation in milk urea nitrogen in Paraná dairy cows. R. Bras. Zootec. 41:692-697. https: //doi.org/http://dx.doi.org/10.1590/S1516-35982012000300032.

Fatehi, F., A. Zali, M. Honarvar, M. Dehghan-Banadaky, A. J. Young, M. Ghiasvand, and M. Eftekhari. 2012. Review of the relationship between milk urea nitrogen and days in milk, parity, and monthly temperature mean in Iranian Holstein cows. J. Dairy Sci. 95:51565163. https://doi.org/10.3168/jds.2011-4349.

Gengler, N., H. Soyeurt, F. Dehareng, C. Bastin, F. Colinet, H. Hammami, M. L. Vanrobays, A. Lainé, S. Vanderick, C. Grelet, A. Vanlierde, E. Froidmont, and P. Dardenne. 2016. Capitalizing on fine milk composition for breeding and management of dairy cows. J. Dairy Sci. 99:4071-4079. https://doi.org/10.3168/jds.2015-10140.

Gengler, N., A. Tijani, G. R. Wiggans, and I. Misztal. 1999. Estimation of (co)variance function coefficients for test day yield with a expectation-maximization restricted maximum likelihood algorithm. J. Dairy Sci. 82:1849.e1-1849.e23. https://doi.org/10.3168/ jds.S0022-0302(99)75417-2.

Glatz-Hoppe, J., A. Boldt, H. Spiekers, E. Mohr, and B. Losand. 2020. Relationship between milk constituents from milk testing and health, feeding, and metabolic data of dairy cows. J. Dairy Sci. 103:10175-10194. https://doi.org/10.3168/jds.2019-17981.

Hojman, D., M. Gips, and E. Ezra. 2005. Association between live body weight and milk urea concentration in Holstein cows. J. Dairy Sci. 88:580-584. https://doi.org/10.3168/jds.S0022-0302(05)72721-1.

Hossein-Zadeh, N. G., and M. Ardalan. 2011. Genetic relationship between milk urea nitrogen and reproductive performance in Holstein dairy cows. Animal 5:26-32. https://doi.org/10.1017/ S1751731110001606.

Hristov, A. N., A. Bannink, L. A. Crompton, P. Huhtanen, M. Kreuzer, M. McGee, P. Nozière, C. K. Reynolds, A. R. Bayat, D. R. Yáñez-Ruiz, J. Dijkstra, E. Kebreab, A. Schwarm, K. J. Shingfield, and Z. Yu. 2019. Invited review: Nitrogen in ruminant nutrition: A review of measurement techniques. J. Dairy Sci. 102:5811-5852. https://doi.org/10.3168/jds.2018-15829.

Jonker, J. S., R. A. Kohn, and R. A. Erdman. 1998. Using milk urea nitrogen to predict nitrogen excretion and utilization efficiency in lactating dairy cows. J. Dairy Sci. 81:2681-2692. https://doi.org/ 10.3168/jds.S0022-0302(98)75825-4.

Kananub, S., P. Pechkerd, J. VanLeeuwen, H. Stryhn, and P. Arunvipas. 2020. Evaluation of influence of milk urea nitrogen on reproductive performance in smallholder dairy farms. Aust. Vet. J. 98:375-379. https://doi.org/10.1111/avj.12946.

Kauffman, A. J., and N. R. St-Pierre. 2001. The relationship of milk urea nitrogen to urine nitrogen excretion in Holstein and Jersey cows. J. Dairy Sci. 84:2284-2294. https://doi.org/10.3168/jds .S0022-0302(01)74675-9.

König, S., Y. M. Chang, U. U. V. Borstel, D. Gianola, and H. Simianer. 2008. Genetic and phenotypic relationships among milk urea nitrogen, fertility, and milk yield in Holstein cows. J. Dairy Sci. 91:4372-4382. https://doi.org/10.3168/jds.2008-1236.

Loker, S., C. Bastin, F. Miglior, A. Sewalem, L. R. Schaeffer, J. Jamrozik, A. Ali, and V. Osborne. 2012. Genetic and environmental relationships between body condition score and milk production traits in Canadian Holsteins. J. Dairy Sci. 95:410-419. https://doi .org/10.3168/jds.2011-4497.

Lopez-villalobos, N., M. CorreaLuna, J. L. Burke, N. W. Sneddon, M. M. Schultz, D. J. Donaghy, and P. D Kemp.. 2018. Genetic parameters for milk urea concentration and milk traits in New Zealand grazing dairy cattle. N. Z. J. Anim. Sci. Prod. 78:56-61.

Marshall, C. J., M. R. Beck, K. Garrett, G. K. Barrell, O. Al-Marashdeh, and P. Gregorini. 2020. Grazing dairy cows with low milk urea nitrogen breeding values excrete less urinary urea nitrogen. Sci. Total Environ. 739:139994. https://doi.org/10.1016/j.scitotenv .2020.139994.

Mayeres, P., J. Stoll, J. Bormann, R. Reents, and N. Gengler. 2004. Prediction of daily milk, fat, and protein production by a random regression test-day model. J. Dairy Sci. 87:1925-1933. https://doi .org/10.3168/jds.S0022-0302(04)73351-2.

Miglior, F., A. Sewalem, J. Jamrozik, J. Bohmanova, D. M. Lefebvre, and R. K. Moore. 2007. Genetic analysis of milk urea nitrogen and lactose and their relationships with other production traits in Canadian Holstein cattle. J. Dairy Sci. 90:2468-2479. https://doi .org/10.3168/jds.2006-487.

Miglior, F., A. Sewalem, J. Jamrozik, D. M. Lefebvre, and R. K. Moore. 2006. Analysis of milk urea nitrogen and lactose and their effect on longevity in Canadian dairy cattle. J. Dairy Sci. 89:48864894. https://doi.org/10.3168/jds.S0022-0302(06)72537-1.

Misztal, I., S. Tsuruta, D. A. L. Lourenco, Y. Masuda, I. Aguilar, A. Legarra, and Z. Vitezica. 2018. Manual for BLUPF90 Family Programs. University of Georgia. Accessed Jan. 6, 2021. http:// nce.ads.uga.edu/wiki/lib/exe/fetch.php?media=blupf90_all7.pdf. 
Mitchell, R. G., G. W. Rogers, C. D. Dechow, J. E. Vallimont, J. B. Cooper, U. Sander-Nielsen, and J. S. Clay. 2005. Milk urea nitrogen concentration: Heritability and genetic correlations with reproductive performance and disease. J. Dairy Sci. 88:4434-4440. https://doi.org/10.3168/jds.S0022-0302(05)73130-1.

Mucha, S., and E. Strandberg. 2011. Genetic analysis of milk urea nitrogen and relationships with yield and fertility across lactation. J. Dairy Sci. 94:5665-5672. https://doi.org/10.3168/jds.2010-3916.

Roy, B., R. K. Mehla, and S. K. Sirohi. 2003. Influence of milk yield, parity, stage of lactation and body weight on urea and protein concentration in milk of Murrah buffaloes. Asian-Australas. J. Anim. Sci. 16:1285-1290. https://doi.org/10.5713/ajas.2003.1285.

Rzewuska, K. and T. Strabel. 2013. Genetic parameters for milk urea concentration and milk traits in Polish Holstein-Friesian cows. J. Appl. Genet. 54:473-482. https://doi.org/10.1007/s13353-013 $-0159-8$

Rzewuska, K., and T. Strabel. 2015. The genetic relationship between reproduction traits and milk urea concentration. Anim. Sci. Pap. Rep. 33:243-256.

Samoré, A. B., C. Romani, A. Rossoni, E. Frigo, O. Pedron, and A. Bagnato. 2007. Genetic parameters for casein and urea content in the Italian Brown Swiss dairy cattle. Ital. J. Anim. Sci. 6(sup1):201-203. https://doi.org/10.4081/ijas.2007.1s.201.

Satoła, A., E. Ptak, W. Jagusiak, and A. Otwinowska-Mindur. 2017b. Genetic relationship of conformation traits with lactose percentage and urea concentration in milk of Polish Holstein-Friesian cows. Anim. Sci. Pap. Rep. 35:241-252.

Satoła, A., E. Ptak, A. Otwinowska-Mindur, and W. Jagusiak. 2017a. Genetic parameters for lactose percentage and urea concentration in milk of polish Holstein-Friesian cows. Anim. Sci. Pap. Rep. 35:159-172.

Siatka, K., A. Sawa, M. Bogucki, and S. Krezel-Czopek. 2020. The effect of milk urea level on fertility parameters in Holstein-Friesian dairy cows. Turk. J. Vet. Anim. Sci. 44:42-46. https://doi.org/10 $.3906 /$ vet-1810-41.

Spek, J. W., J. Dijkstra, G. Van Duinkerken, and A. Bannink. 2013. A review of factors influencing milk urea concentration and its relationship with urinary urea excretion in lactating dairy cattle. J. Agric. Sci. 151:407-423. https://doi.org/10.1017/ S0021859612000561.

Stoop, W. M., H. Bovenhuis, and J. A. M. van Arendonk. 2007. Genetic parameters for milk urea nitrogen in relation to milk production traits. J. Dairy Sci. 90:1981-1986. https://doi.org/10.3168/ jds.2006-434.

Stranden, I., M. Lidauer, E. A. Mäntysaari, and J. Pösö. 2000. Calculation of Interbull weighting factors for the Finnish test day model. Interbull Bull. 26:78-79

Vanderick, S., R. R. Mota, K. Wijnrocs, and N. Gengler. 2020. Description of the genetic evaluation systems used in the Walloon Region of Belgium. Accessed Jan. 6, 2021. http://www.elinfo.be/ docs/GESen2012.pdf.

Wood, G. M., P. J. Boettcher, J. Jamrozik, G. B. Jansen, and D. F. Kelton. 2003. Estimation of genetic parameters for concentrations of milk urea nitrogen. J. Dairy Sci. 86:2462-2469. https://doi.org/ 10.3168/jds.S0022-0302(03)73840-5.

Yin, T., B. Bapst, U. U. V. Borstel, H. Simianer, and S. König. 2012. Genetic parameters for gaussian and categorical traits in organic and low input dairy cattle herds based on random regression methodology. Livest. Sci. 147:159-169. https://doi.org/10.1016/j.livsci .2012.04.017.

\section{ORCIDS}

Y. Chen (ํ) https://orcid.org/0000-0002-8593-4384

H. Atashi $\odot$ https://orcid.org/0000-0002-6853-6608

S. Vanderick $\odot$ https://orcid.org/0000-0003-4556-4718

R. R. Mota ๑ https://orcid.org/0000-0003-0566-3236

H. Soyeurt @ https://orcid.org/0000-0001-9883-9047

H. Hammami ๑ https://orcid.org/0000-0003-4751-6699

N. Gengler ๑ https://orcid.org/0000-0002-5981-5509 